\title{
Seasonal influenza vaccination coverage and its determinants among nursing homes personnel in western France
}

\author{
Christelle Elias ${ }^{1,2 \dagger}$, Anna Fournier ${ }^{1,2 \dagger}$, Anca Vasiliu ${ }^{1,2}$, Nicolas Beix ${ }^{1,2}$, Rémi Demillac ${ }^{1,3}$, Hélène Tillaut ${ }^{4}$, \\ Yvonnick Guillois ${ }^{4}$, Serge Eyebe ${ }^{1,2}$, Bastien Mollo $0^{1,2}$ and Pascal Crépey ${ }^{1,5,6^{*}}$
}

\begin{abstract}
Background: Influenza-associated deaths is an important risk for the elderly in nursing homes (NHs) worldwide. Vaccination coverage among residents is high but poorly effective due to immunosenescence. Hence, vaccination of personnel is an efficient way to protect residents. Our objective was to quantify the seasonal influenza vaccination (IV) coverage among NH for elderly workers and identify its determinants in France.

Methods: We conducted a cross-sectional study in March 2016 in a randomized sample of NHs of the Ille-et-Vilaine department of Brittany, in western France. A standardized questionnaire was administered to a randomized sample of NH workers for face-to-face interviews. General data about the establishment was also collected.

Results: Among the $33 \mathrm{NHs}$ surveyed, IV coverage for the 2015-2016 season among permanent workers was estimated at 20\% (95\% Confidence Interval (CI) 15.3\%-26.4\%) ranging from 0\% to 69\% depending on the establishments surveyed. Moreover, IV was associated with having previously experienced a "severe" influenza episode in the past (Prevalence Ratio 1.48, 95\% Cl 1.01-2.17), and varied by professional categories $(p<0.004)$ with better coverage among administrative staff. Better knowledge about influenza prevention tools was also correlated $(p<0.001)$ with a higher IV coverage. Individual perceptions of vaccination benefits had a significant influence on the IV coverage $(p<0.001)$. Although IV coverage did not reach a high rate, our study showed that personnel considered themselves sufficiently informed about IV.

Conclusions: IV coverage remains low in the $\mathrm{NH}$ worker population in Ille-et-Vilaine and also possibly in France. Strong variations of IV coverage among NHs suggest that management and working environment play an important role. To overcome vaccine "hesitancy", specific communication tools may be required to be adapted to the various NH professionals to improve influenza prevention.
\end{abstract}

Keywords: Influenza vaccination, Nursing homes, Vaccination coverage, Cross-sectional study, France

\section{Background}

Seasonal influenza epidemics are a major public health problem worldwide, increasing annually the morbidity and mortality burden in vulnerable populations, particularly children younger than 2 years old and adults aged 65 years and older. Structures that concentrate vulnerable

\footnotetext{
* Correspondence: pascal.crepey@ehesp.fr

${ }^{\dagger}$ Equal contributors

${ }^{1}$ Ecole des Hautes Etudes en Santé Publique, Université Sorbonne Paris Cité Rennes, France

5UMR "Emergence des Pathologies Virales", Aix-Marseille University - IRD 190

- Inserm 1207 - EHESP, Marseille, France

Full list of author information is available at the end of the article
}

populations such as nursing homes for the elderly (NHs) or other long-term care facilities require special public health attention $[1,2]$. Despite a high coverage of influenza vaccination (IV) among $\mathrm{NH}$ residents, influenza remains a major cause of death in this population [3].

Elderly people are poorly protected by vaccination due to immunosenescence [4]. Hence, prevention of influenza cases relies mainly on preventing infection among their direct contacts - an indirect protection strategy. In NHs, preventing influenza cases and deaths depends on preventing the virus from entering the community via the vaccination of healthcare workers $(\mathrm{HCW})$ and other $\mathrm{NH}$ workers 
$[5,6]$. Consequently, improving $\mathrm{NH}$ workers' IV rate is a major public health target to alleviate the morbidity and mortality burden of influenza in the elderly population. In fact, $10 \%$ to $30 \%$ of $\mathrm{HCW}$ are infected with influenza each winter [7, 8], and most continue to work [9] which may lead to transmission of the virus to patients. Moreover, immunizing $\mathrm{NH}$ workers has been shown to decrease influenza transmission which increases the benefits of vaccination $[5,6]$.

IV of at least $75 \%$ of personnel is recommended by World Health Organization (WHO), CDC and the French Ministry of Health $[10,11]$. In the US, various interventions performed in long-term facilities have contributed to an increase in HCW IV coverage from $36 \%$ in 2003 [12] to $86.4 \%$ in 2015 [13]. In France, HCW IV coverage, far from the WHO target, was $33.6 \%$ in 2008 and $25.6 \%$ in 2009 [3, 7, 8, 14-18].

In order to globally improve NH workers' IV coverage, it is important to understand the determinants driving the vaccination status, particularly in settings with low coverage. The primary objective of the study is to estimate the IV coverage for the 2015-2016 winter season in $\mathrm{NH}$ workers in Ille-et-Vilaine, a department of the Brittany region, located in western France. Secondary objectives aim to assess the factors related to IV among $\mathrm{NH}$ workers.

\section{Methods}

\section{Study design and population}

A cross-sectional study was conducted among $\mathrm{NH}$ workers in French NHs in Ille-et-Vilaine (Fig. 1). The study took place on March 22nd 2016 and was performed as a collaboration between the French School of Public Health and Santé Publique France, in association with the regional health authority of Brittany. We performed a two-step randomized sampling, by randomly selecting NHs, then participants among the NHs. A sample size of 640 participants was computed based on an IV coverage estimation of 35\%, an acceptance rate of $80 \%$, an alpha risk of $5 \%$, a study power of $80 \%$, and a clustering effect. We randomly selected $40 \mathrm{NHs}$ among the $137 \mathrm{NHs}$ located in Ille-et-Vilaine and secondly, 16 $\mathrm{NH}$ workers were randomly chosen from each nursing home. Only permanent staff present at the time of the survey between 9 am and 7 pm were included, whereas temporary staff, interns, and liberal practitioners were excluded. No distinction between full time or part time workers was undertaken. In our study, $\mathrm{NH}$ workers included HCW such as physicians, nurses or pharmacists, administrative staff as well as facility and logistic staff. In order to reduce refusals, a letter introducing the survey was sent two weeks before the survey to the selected NHs.

\section{Data collection}

Data was collected through two standardized and pretested questionnaires given as Additional files: 1, 2, 3 and 4. Questionnaire were prepared in workgroups over a two-day period where outcomes, analysis plan and variables were defined. Questions to $\mathrm{NH}$ managers and $\mathrm{NH}$ workers were then drafted and both questionnaires were tested on a sample of $1 \mathrm{NH}$ manager and $5 \mathrm{NH}$ workers

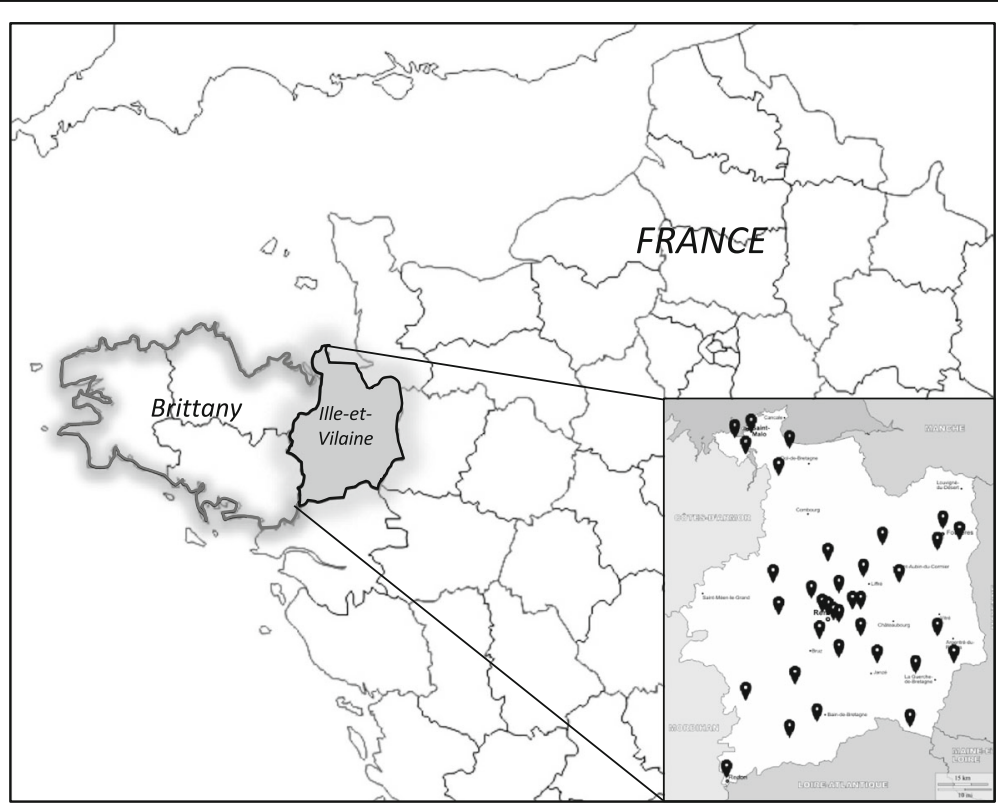

Fig. 1 Map of the 33 nursing homes surveyed in the Ille-et-Vilaine department 
(3 physicians and 2 nurses). The first questionnaire was addressed to $\mathrm{NH}$ managers to obtain information about their establishment. We gathered $\mathrm{NH}$ status, size and information about vaccination (information or campaign) of the $\mathrm{NH}$ workers. The second questionnaire, targeting $\mathrm{NH}$ workers, was divided in three main parts: the first focused on socio-demographic items such as gender, age, occupation and experience in a $\mathrm{NH}$; the second questioned $\mathrm{NH}$ workers on influenza risk factors and IV history; and finally, the third part gathered information concerning knowledge about vaccination as well as the perceived benefits and barriers of influenza vaccination. The total duration of the survey lasted no more than five minutes. Both questionnaires were administered in their original language (French). All questions were closed but interviewees were offered the possibility to give final comments or remarks. Questionnaires were administered face-to-face to $\mathrm{NH}$ workers in the participating NHs. All interviews were realized by 31 trained investigators as part of the IDEA international field epidemiology training course.

\section{Data analysis}

Vaccine coverage was estimated from data obtained from the interviews with the personnel. IV coverage was defined as the proportion of vaccinated $\mathrm{NH}$ workers for the 2015-2016 winter season. We first conducted a univariate analysis using Chi2 and Fisher exact tests to determine which determinants were significantly associated with vaccine coverage. All factors with $p$ values lower than 0.2 were integrated in a multivariate Poisson model with and without random effects. Prevalence ratios (PR) and their 95\% confidence intervals (CI) were used as measures of association. A $p$ value lower than 0.05 was considered to be statistically significant. Data were centralized with WEPI software (Epiconcept) and analyses were performed using Stata $13^{\circ}$ (StataCorp, Texas, USA).

\section{Results}

\section{Participation}

Of the $40 \mathrm{NHs}$ randomized among the 137 in the administrative district, 33 (85\%) participated in this survey. Two refused and 5 could not be visited for logistic reasons. Of the 485 personnel surveyed, 480 answered and 5 refused principally due to lack of time (response rate 99\%) (Fig. 2). We excluded three responders who did not match inclusion criteria to finally include a total of $477 \mathrm{NH}$ workers in our study.

\section{Characteristics of nursing homes and workers}

Among NHs, $52.5 \%$ were public versus $47.5 \%$ with a private status, with a median number of 71 beds (min 28; max 270) (Table 1). The median number of permanent

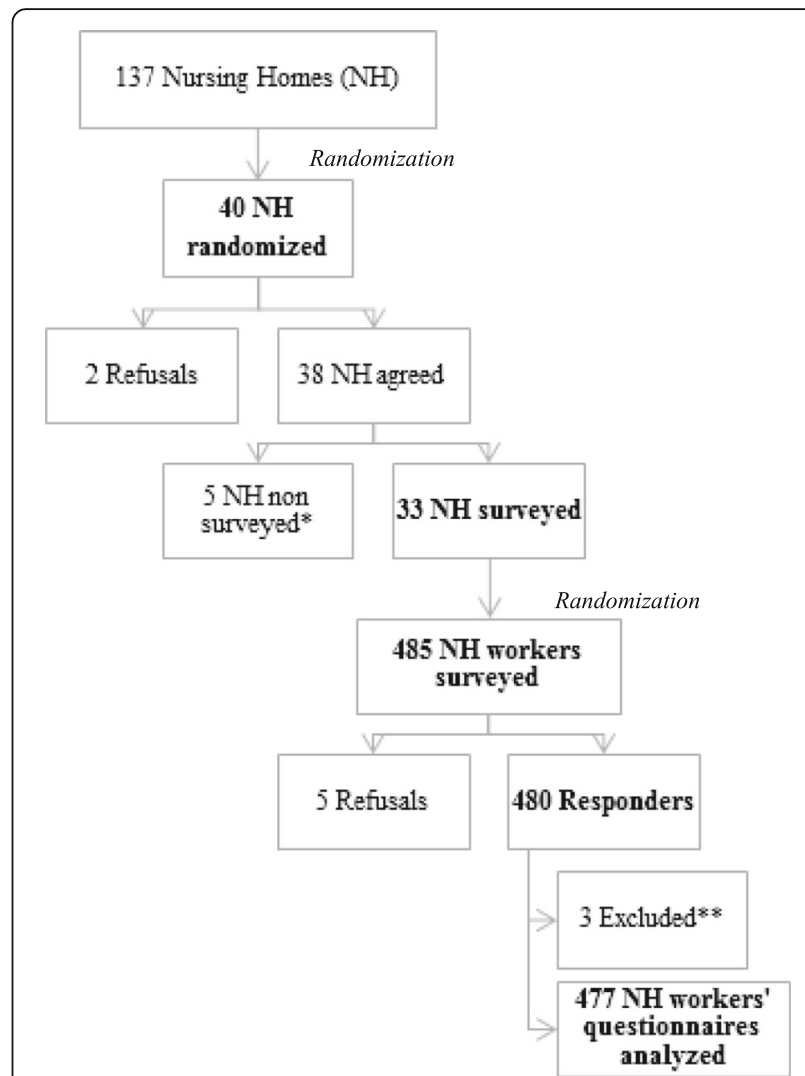

Fig. 2 Study sample flow chart. *Late arrival or acute gastro enterities epidemic in $\mathrm{NH} .{ }^{*}$ We excluded three responders who were not matching inclusion cirteria

personnel was $43(\min 23$; $\max 111)$ and the median ratio employee/resident was 0.73 ( $\min 0.42 ; \max 1.33)$.

Concerning the IV campaign, $81.8 \%$ of $\mathrm{NH}$ managers declared they had given information and offered the possibility of vaccination to the $\mathrm{NH}$ workers. Of the total study sample, $87.0 \%$ of $\mathrm{NH}$ workers were female. The mean age was 41 years $(\min 20 ; \max 66)$, and they worked in a NHs for an average of 11.5 years (min 0.6; max 38). Most of them were HCW (42.9\%) or facilities and logistics staff (35.7\%). Administrative positions were held by $11 \%$ of workers. Overall, $84.1 \%$ of $\mathrm{NH}$ workers declared to be in contact with residents more than once per day.

\section{Influenza vaccination coverage among workers}

Of all $\mathrm{NH}$ workers, $20.0 \%$ [95\% CI 15.3\%-26.4\%] declared having received the IV during the 2015/16 season, among which $80 \%$ have been vaccinated within the establishment. 21.3\% [95\% CI 16.6\%-27.3\%] of them reported being regularly vaccinated, as defined by at least two vaccinations during the last three years.

Median IV coverage for all sampled establishments for the season 2015-2016 was estimated at 18.2\% ranging from $0 \%$ to a maximum of $69.2 \%$ (Fig. 3). 
Table 1 Population according to the nursing home characteristics

\begin{tabular}{|c|c|c|c|c|c|}
\hline \multirow[b]{2}{*}{ Factors } & \multirow[b]{2}{*}{$\begin{array}{l}\text { Proportion of the } \\
\text { personnel (\%) }\end{array}$} & \multirow[b]{2}{*}{$95 \% \mathrm{Cl}$} & \multicolumn{3}{|c|}{ Bivariate analysis with random effect } \\
\hline & & & $\begin{array}{l}\text { Vaccination } \\
\text { coverage (\%) }\end{array}$ & $95 \% \mathrm{Cl}$ & $p$-value \\
\hline \multicolumn{6}{|l|}{ Institution type } \\
\hline Status of the establishment & & & & & 0.34 \\
\hline Public establishment & 52.5 & {$[48.1-56.9]$} & 25.5 & {$[14.5-32.8]$} & \\
\hline Private establishment & 47.5 & {$[43.2-51.9]$} & 17.5 & {$[12.5-24.1]$} & \\
\hline Vaccination campaign & & & & & 0.93 \\
\hline Working in an institution without campaign & 16.3 & {$[7.6-31.7]$} & 19.4 & {$[6.6-45.2]$} & \\
\hline Working in an institution with campaign & 83.6 & [68.3-92.4] & 20.3 & [15.4-26.2] & \\
\hline
\end{tabular}

\section{Predictors of influenza vaccine uptake}

\section{Socio-demographic, influenza risk factors, and vaccine} history predictors

Vaccinated $\mathrm{NH}$ workers were older than the nonvaccinated (Table 2). Statistical analysis showed that personnel aged above 30 years were more vaccinated than personnel between 20 and 29 years $(p<0.01)$. A lower vaccine coverage was observed among the facilities and logistic staff members relative to the $\mathrm{HCW}$ $(p<0.004)$. Furthermore, having experienced a "severe" influenza infection (defined as "you had to be bedridden") was positively associated with a higher vaccination rate $(p<0.045)$ (Table 2$)$.

\section{Knowledge about influenza}

About $\mathrm{NH}$ workers' knowledges of influenza and IV, $75.0 \%$ of them spontaneously mentioned hand washing as a prevention tool to avoid influenza transmission (Table 3). Wearing a mask and gloves was listed by $49.5 \%$ of $\mathrm{NH}$ workers, preventing contacts by $27.6 \%$ and vaccination by $24.4 \%$. Knowledge of recommended prevention tools against transmission of influenza viruses

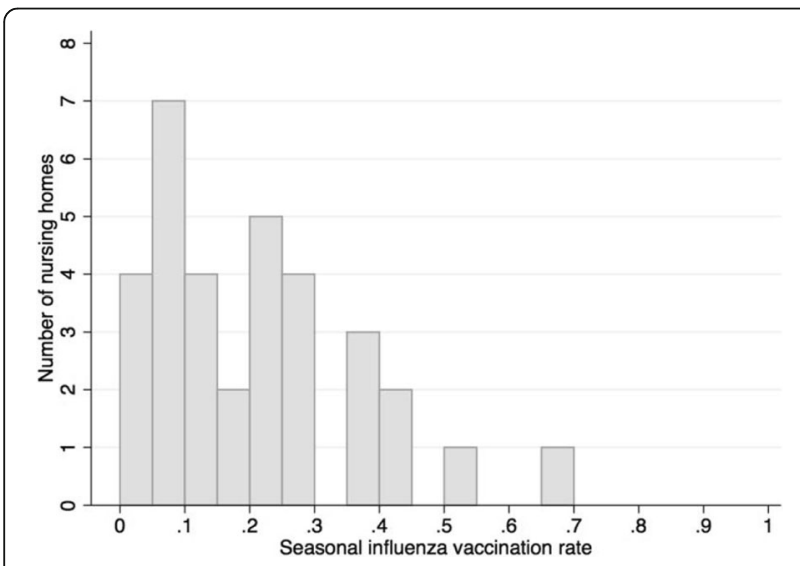

Fig. 3 Distribution of the nursing homes according to their rate of seasonal influenza vaccination was significantly associated with IV coverage. Spontaneous citation of one or more prevention tools was positively associated with a higher rate of vaccination $(p<0.001)$. An increasing association between the number of tools spontaneously cited and IV coverage was observed $(p<0.001)$. Moreover, 9.2\% of $\mathrm{NH}$ workers reported homeopathy and $26.4 \%$ pointed out other tools not recommended by the national health authorities.

Finally, 73.9\% of employees knew that IV needs to be administrated every year. And, knowledge of the frequency of the vaccination, known by a large part of the employees, was positively associated with a higher vaccination rate $(p<0.001)$. (Table 3$)$.

\section{Information}

The main channels of information about seasonal IV received by the $\mathrm{NH}$ workers were primarily communication within the establishment and secondly communication by the media (Table 3 ). We also observed that $53.7 \%$ of the administrative employees were sensitive to posters as a medium. There were $51.9 \%$ of the HCW and $55.1 \%$ of the facilities and logistics staff that stated being more receptive to meetings and trainings (Table 4).

\section{Perceived benefits of influenza vaccination}

Perceived benefits and barriers to seasonal IV are shown in Table 5. Among the employees, $73.7 \%$ agreed that being vaccinated protects the $\mathrm{NH}$ residents. This proportion is also high for the non-vaccinated $\mathrm{NH}$ workers (74.1\%). Otherwise, 52.9\% $\mathrm{NH}$ workers agreed with the fact that being vaccinated prevents oneself from getting influenza.

\section{Perceived barriers to influenza vaccination}

Table 5 shows that $33.4 \%$ of $\mathrm{NH}$ workers thought that the influenza vaccine is ineffective and $24.1 \%$ of $\mathrm{NH}$ workers believed that the promotion of the vaccine was only linked to financial interests. Finally, 26.9\% $\mathrm{NH}$ workers were convinced that seasonal IV causes serious side effects and $17.1 \%$ cited financial costs as a barrier. 
Table 2 Characteristics of the NH personnel and their seasonal IV coverage

\begin{tabular}{|c|c|c|c|c|c|c|c|c|}
\hline \multirow[b]{2}{*}{ Characteristics } & \multirow[b]{2}{*}{$\begin{array}{l}\text { Proportion of the } \\
\text { personnel (\%) }\end{array}$} & \multirow[b]{2}{*}{$95 \% \mathrm{Cl}$} & \multicolumn{3}{|c|}{ Bivariate analysis with random effect } & \multicolumn{3}{|c|}{ Multivariate analysis with random effect } \\
\hline & & & $\begin{array}{l}\text { Vaccination } \\
\text { coverage }(\%)\end{array}$ & $95 \% \mathrm{Cl}$ & $p$-value & $\overline{P R}$ & $95 \% \mathrm{Cl}$ & $p$-value \\
\hline \multicolumn{9}{|l|}{ Socio-demographics } \\
\hline Sex & & & & & 0.31 & & & \\
\hline Male & 13.0 & {$[10.0-17.0]$} & 24.6 & {$[15.4-36.7]$} & & & & \\
\hline Female & 87.0 & {$[83.2-90.0]$} & 19.5 & {$[14.5-25.7]$} & & & & \\
\hline Mean age & & & & & 0.008 & & & \\
\hline Age: $20-29$ yrs & 17.8 & {$[14.2-22.2]$} & 7.0 & {$[3.6-13.0]$} & & ref. & - & \\
\hline Age: $30-39$ yrs & 28.6 & {$[24.2-33.5]$} & 21.6 & {$[15.0-30.1]$} & & 2.95 & {$[1.51-5.76]$} & 0.003 \\
\hline Age: $40-49$ yrs & 29.6 & {$[25.9-33.6]$} & 26.3 & {$[18.0-36.6]$} & & 3.45 & {$[1.86-6.41]$} & $<0.001$ \\
\hline Age: $50-59$ yrs & 20.9 & {$[17.0-25.4]$} & 20.3 & {$[12.2-31.9]$} & & 2.81 & {$[1.28-6.16]$} & 0.012 \\
\hline Age: $60-69$ yrs & 3.1 & {$[1.9-5.1]$} & 26.8 & {$[11.8-49.9]$} & & 2.91 & {$[1.02-8.34]$} & 0.043 \\
\hline Mean institution working length & & & & & 0.26 & & & \\
\hline Working length: $0-5$ yrs & 26.2 & {$[21.1-32.1]$} & 15.1 & {$[7.6-27.8]$} & & & & \\
\hline Working length: 5-10 yrs & 31.6 & {$[26.6-37.2]$} & 15.8 & {$[8.3-27.8]$} & & & & \\
\hline Working length: $10-15$ yrs & 18.6 & [15.4-22.4] & 27.3 & {$[18.3-38.6]$} & & & & \\
\hline Working length: 15-20 yrs & 14.6 & {$[11.1-19.0]$} & 21.8 & {$[13.4-33.5]$} & & & & \\
\hline Working length: $>20$ yrs & 8.9 & {$[6.5-12.1]$} & 25.1 & {$[13.7-41.2]$} & & & & \\
\hline Occupation classification & & & & & 0.004 & & & \\
\hline Healthcare workers & 42.9 & {$[37.7-48.2]$} & 24.9 & {$[18.4-32.6]$} & & ref. & - & \\
\hline Administrative & 11.0 & {$[8.5-14.1]$} & 31.0 & {$[18.5-47.0]$} & & 1.07 & {$[0.74-1.55]$} & 0.86 \\
\hline Facilities and logistics & 35.7 & {$[31.0-40.6]$} & 13.1 & {$[8.3-20.2]$} & & 0.53 & {$[0.36-0.77]$} & 0.003 \\
\hline Other & 10.5 & {$[7.8-14.1]$} & 14.2 & {$[6.7-27.7]$} & & 0.49 & {$[0.25-0.98]$} & 0.045 \\
\hline \multicolumn{9}{|l|}{ Contacts with residents } \\
\hline Frequency of contacts with residents & & & & & 0.96 & & & \\
\hline Rarely (<=1/day) & 15.6 & {$[12.2-20.6]$} & 20.4 & {$[11.1-34.5]$} & & & & \\
\hline Several times/day (>1/day) & 84.1 & {$[79.4-87.8]$} & 20.1 & {$[15.3-25.9]$} & & & & \\
\hline \multicolumn{9}{|l|}{ Influenza vaccine risk factors } \\
\hline Living with children $<5$ yrs & 23.0 & {$[18.9-27.7]$} & 21.7 & {$[14.0-32.1]$} & 0.9 & & & \\
\hline Living with elderly person $>65$ yrs & 4.4 & {$[2.7-7.1]$} & 19.0 & {$[7.6-40.2]$} & 0.9 & & & \\
\hline Living with someone with chronic illness & 8.3 & {$[6.0-11.3]$} & 30.6 & {$[18.4-46.4]$} & 0.033 & & & \\
\hline $\begin{array}{l}\text { Living with someone with influenza risk } \\
\text { factor (total) }\end{array}$ & 31.6 & {$[27.3-36.3]$} & 25.2 & {$[17.5-34.9]$} & 0.09 & & & \\
\hline $\begin{array}{l}\text { Having a personal medical indication to } \\
\text { vaccination }\end{array}$ & 9.5 & {$[7.3-12.5]$} & 26.5 & {$[14.9-42.6]$} & 0.33 & & & \\
\hline \multicolumn{9}{|l|}{ Influenza history } \\
\hline Previous "severe" influenza infection & 39.1 & [35.8-42.5] & 27.7 & [19.8-37.3] & 0.003 & 1.48 & {$[1.01-2.17]$} & 0.045 \\
\hline
\end{tabular}

adjusted on the number of permanent worker, the number of prevention tools spontaneously mentioned and the knowledge of frequency of the vaccination

\section{Discussion}

The French Ministry of Health has set a $75 \%$ target for seasonal IV coverage among NH workers; however, our study estimates the 2015-2016 seasonal IV coverage in Ille-et-Vilaine, in this population, to be $20.0 \%$ [15.3\%26.4\%]. Vaux et al. [19] reported a 33.6\% IV coverage in French NH workers for the 2007-2008 season. Contrary to our study, their study was also showing that private
NHs had higher coverage rates than public ones $(45.2 \%$ versus 29.8\%, $p<0.001)$. However, Vaux et al. [19] used data declared by $\mathrm{NH}$ management and not direct $\mathrm{NH}$ workers interviews, which may introduce bias and prevent the identification of factors linked to individual perception and knowledge.

Social influence may explain the high IV coverage heterogeneity observed in our NH sample, from $0 \%$ to $69 \%$, 
Table $3 \mathrm{NH}$ personnel knowledge and perception on influenza and the seasonal IV coverage

\begin{tabular}{|c|c|c|c|c|c|c|c|c|}
\hline \multirow{2}{*}{ Factors } & \multirow[b]{2}{*}{$\begin{array}{l}\text { Proportion of the } \\
\text { personnel (\%) }\end{array}$} & \multirow[b]{2}{*}{$95 \% \mathrm{Cl}$} & \multicolumn{3}{|c|}{ Bivariate analysis with random effect } & \multicolumn{3}{|c|}{ Multivariate analysis with random effect ${ }^{\mathrm{a}}$} \\
\hline & & & $\begin{array}{l}\text { Vaccination } \\
\text { coverage (\%) }\end{array}$ & $95 \% \mathrm{Cl}$ & $p$-value & $P R$ & $95 \%$ IC & $p$-value \\
\hline \multicolumn{9}{|l|}{ Knowledge to prevent influenza transmission } \\
\hline $\begin{array}{l}\text { Number of prevention tools spontaneously } \\
\text { mentioned }\end{array}$ & & & & & $<0.001$ & & & \\
\hline 0 prevention tool & 10.0 & {$[7.7-13.0]$} & 2.2 & {$[0.3-14.0]$} & & ref. & - & \\
\hline 1 prevention tool & 26.9 & {$[23.0-31.3]$} & 15.1 & {$[9.0-24.1]$} & & 6.48 & [1.18-35.57] & 0.034 \\
\hline 2 prevention tools & 40.7 & {$[35.7-45.8]$} & 21.2 & [15.8-28.0] & & 7.75 & {$[1.21-49.70]$} & 0.037 \\
\hline 3 prevention tools & 21.1 & {$[17.6-25.1]$} & 32.3 & {$[21.2-45.8]$} & & 9.27 & [1.51-56.67] & 0.022 \\
\hline 4 prevention tools or more & 1.3 & {$[0.5-3.0]$} & 33.3 & {$[7.3-76.2]$} & & 11.03 & {$[1.27-96.24]$} & 0.039 \\
\hline Vaccination & 24.4 & {$[20.2-29.2]$} & 43.5 & {$[30.9-57.0]$} & $<0.001$ & & & \\
\hline Hands washing & 75.0 & {$[70.5-79.1]$} & 21.5 & [16.1-28.1] & 0.20 & & & \\
\hline Wearing mask / gloves & 49.5 & {$[43.6-55.5]$} & 22.2 & [16.1-29.8] & 0.27 & & & \\
\hline Prevent the contacts & 27.6 & {$[22.1-33.9]$} & 20.7 & {$[14.0-29.4]$} & 0.86 & & & \\
\hline \multicolumn{9}{|c|}{ Other tools spontaneously mentioned to prevent influenza transmission } \\
\hline Homeopathy & 9.2 & {$[6.0-13.9]$} & 9.4 & [3.4-23.5] & 0.06 & & & \\
\hline Anti-viral therapy & 0.2 & {$[0.0-1.5]$} & 0.0 & & 0.07 & & & \\
\hline Do not know & 4.4 & {$[2.6-7.4]$} & 19.7 & {$[14.2-26.7]$} & 0.06 & & & \\
\hline \multicolumn{9}{|l|}{ Knowledge of the populations at risk } \\
\hline $\begin{array}{l}\text { Number of population at risk spontaneously } \\
\text { mentioned }\end{array}$ & & & & & 0.15 & & & \\
\hline 2 populations cited or less & 69.7 & {$[64.3-74.7]$} & 18.2 & [13.3-24.4] & & & & \\
\hline 3 populations cited or more & 30.3 & {$[25.3-35.7]$} & 24.6 & [16.4-35.2] & & & & \\
\hline Elderly person $>65$ yrs & 95.8 & [93.6-97.3] & 20.4 & [15.3-26.6] & 0.59 & & & \\
\hline Infants and young children & 66.4 & {$[61.9-70.6]$} & 20.0 & {$[14.0-27.6]$} & 0.1 & & & \\
\hline Person with chronic illness & 43.9 & {$[39.4-48.5]$} & 26.4 & {$[20.0-34.1]$} & $<0.001$ & & & \\
\hline Pregnant women & 3.4 & {$[2.1-5.3]$} & 6.4 & {$[0.8-35.8]$} & 0.16 & & & \\
\hline Overweight person & 0.0 & - & - & & & & & \\
\hline Do not know & 1.6 & {$[0.8-3.2]$} & 13.3 & {$[1.8-56.2]$} & 0.63 & & & \\
\hline \multicolumn{9}{|l|}{ Knowledge of frequency of the vaccination } \\
\hline Knowledge of frequency of the vaccination & & & & & $<0.001$ & & & \\
\hline Other or do not known & 26.1 & [21.5-31.3] & 4.8 & {$[2.3-9.7]$} & & & & \\
\hline Every year & 73.9 & {$[68.7-78.5]$} & 25.5 & [19.1-33.2] & & 4.27 & {$[1.96-9.31]$} & $<0.001$ \\
\hline \multicolumn{9}{|l|}{ Information channels for vaccination } \\
\hline By the NHs & 76.3 & {$[69.4-82.1]$} & 20.8 & {$[15.5-27.4]$} & 0.52 & & & \\
\hline By media & 67.5 & {$[62.5-72.2]$} & 19.8 & {$[14.0-27.3]$} & 0.81 & & & \\
\hline By general practitioner & 11.4 & {$[8.9-14.5]$} & 33.7 & {$[21.1-49.2]$} & 0.005 & & & \\
\hline By occupational practitioner & 5.7 & {$[3.6-9.1]$} & 36.8 & {$[22.2-54.3]$} & 0.009 & & & \\
\hline Other & 12.4 & {$[9.3-16.3]$} & - & & & & & \\
\hline \multicolumn{9}{|l|}{ Sensitivity to information } \\
\hline Theses information's influenced the choice & 13.7 & [10.3-18.0] & 56.6 & {$[41.0-71.0]$} & $<0.001$ & & & \\
\hline Information seems sufficient & 78.4 & {$[72.7-83.1]$} & 21.1 & {$[15.8-27.6]$} & 0.32 & & & \\
\hline Sensitive to posters & 39.7 & {$[34.4-45.2]$} & - & & & & & \\
\hline Sensitive to email, mail & 27.9 & {$[23.8-32.5]$} & - & & & & & \\
\hline Sensitive to meetings and formations & 52.9 & {$[47.6-58.0]$} & - & & & & & \\
\hline Sensitive to other information & 12.5 & [9.2-16.9] & - & & & & & \\
\hline
\end{tabular}

\footnotetext{
${ }^{a}$ Adjusted on the age, the number of $\mathrm{NH}$ personnel, the working length in an institution and the previous "severe" influenza infection
} 
Table $4 \mathrm{NH}$ personnel information type preference

\begin{tabular}{|c|c|c|c|c|c|c|}
\hline \multirow[b]{2}{*}{ Factors } & \multicolumn{6}{|c|}{ Sensitivity to information } \\
\hline & $\begin{array}{l}\text { Sensitive to } \\
\text { posters (\%) }\end{array}$ & $95 \% \mathrm{Cl}$ & $\begin{array}{l}\text { Sensitive to email, } \\
\text { mail (\%) }\end{array}$ & $95 \% \mathrm{Cl}$ & $\begin{array}{l}\text { Sensitive to meetings } \\
\text { and formations (\%) }\end{array}$ & $95 \% \mathrm{Cl}$ \\
\hline \multicolumn{7}{|l|}{ Occupation classification } \\
\hline Healthcare workers & 40.7 & {$[34.4-47.3]$} & 29.0 & {$[23.1-35.6]$} & 51.9 & {$[44.4-59.3]$} \\
\hline Administrative & 53.7 & {$[41.0-66.0]$} & 29.0 & [17.7-43.6] & 36.6 & [21.9-54.3] \\
\hline Facilities and logistics & 36.8 & [29.7-44.6] & 29.5 & [23.6-36.2] & 55.1 & [46.5-63.5] \\
\hline
\end{tabular}

which is consistent with previous studies showing that social influence plays a major role in the decision of vaccination. Studies have found that having a relationship (being a colleague or relative) with people who receive or recommend influenza vaccination is a factor associated to being vaccinated against influenza $(p<0.012)$. Having a NH director or/and NH physician highly invested in the promotion of IV, has also a strong positive impact on $\mathrm{NH}$ workers vaccination $(p<0,001)$ [14, 20, 21].

Regarding occupational determinants, we show a significantly higher coverage in administrative staff compared to $\mathrm{HCW}$. This may be explained by the fact that different staff may be sensitive to different kinds of information. We observe strong variations by occupation concerning the preferred communication medium: posters for most of the administrative staff (53.7\%) and meetings for most HCW (51.9\%). Presently, IV campaigns in French NHs seem to be inefficient; indeed, knowing that a campaign occurred is not significantly link to IV. Looking at individual score of knowledge and perception, our study illustrates a major paradox: firstly, we show that knowledge about means of preventing influenza transmission is highly associated with seasonal IV. Most personnel knew that influenza infection could be avoided by washing their hands, wearing masks and gloves, or avoiding contact with infected people. Of note, "homeopathic vaccine" was also cited by close to $10 \%$ of personnel and was proposed by some facilities as an alternative to the real vaccine. In addition, $52.9 \%$ of the participants knew that being vaccinated could prevent them from being sick (half of the non-vaccinated), and $73.7 \%$ stated that their own vaccination could protect $\mathrm{NH}$ residents (two thirds of the non-vaccinated employees). These figures showed that improved education of personnel may play a role in promoting vaccination.

Communication that counters inaccurate beliefs may also need to be specifically implemented. In our study, a third of $\mathrm{NH}$ workers interviewed believed that influenza vaccine was ineffective and $26.9 \%$ said that it should be avoided due to its side effects. Recent influenza related epidemic events, such as the scare in 2004 of an avian $\mathrm{A} / \mathrm{H} 5 \mathrm{~N} 1$ influenza pandemic, or more recently, the 2009-2010 A/H1N1 pandemic, may have led to influenza communication fatigue or desensitization [20]]. In the Looijmans study, media attention to avian influenza appeared as a positive factor for vaccination (OR 2.24, 95\% CI 1.12-4.50), contrary to the 2009-2010 pandemic that did not show any effect [22, 23]. Mass media coverage and health authorities' communication may have

Table 5 NH personnel perceived benefits and barriers of seasonal influenza vaccination 2015-2016

\begin{tabular}{|c|c|c|c|c|}
\hline Factors & $\begin{array}{l}\text { Proportion of the } \\
\text { personnel (\%) }\end{array}$ & $95 \% \mathrm{Cl}$ & $\begin{array}{l}\text { Vaccination } \\
\text { coverage (\%) }\end{array}$ & $95 \% \mathrm{Cl}$ \\
\hline \multicolumn{5}{|l|}{ Perceived benefits of vaccination } \\
\hline Getting the vaccine will prevent me from getting influenza & 52.9 & {$[47.9-57.8]$} & 32.4 & {$[24.8-41.1]$} \\
\hline When you are vaccinated, you protect your entourage & 68.4 & {$[62.6-73.7]$} & 26.3 & {$[20.1-33.6]$} \\
\hline When you are vaccinated, you protect the institution's residents & 73.7 & {$[68.2-78.6]$} & 25.9 & [19.6-33.2] \\
\hline \multicolumn{5}{|l|}{ Perceived barriers to accepting vaccination } \\
\hline Getting the vaccine is expensive & 17.1 & [13.3-21.7] & 8.9 & {$[4.2-17.8]$} \\
\hline The flu vaccine is ineffective & 33.4 & {$[28.5-38.7]$} & 7.1 & {$[4.3-11.4]$} \\
\hline Avoid the flu vaccine because it causes serious side effects & 26.9 & {$[23.4-30.6]$} & 4.8 & {$[2.3-9.7]$} \\
\hline The seasonal flu vaccine is not recommended by my doctor & 6.1 & {$[4.3-8.5]$} & 3.7 & {$[0.5-22.4]$} \\
\hline Getting vaccinated is taking too long & 0.4 & {$[0.1-1.5]$} & 0.0 & \\
\hline The promotion of the vaccine is only linked to financial interests & 24.1 & {$[20.1-28.5]$} & 4.3 & {$[1.8-9.7]$} \\
\hline
\end{tabular}


been unable to counter polemics and rumors spread via other channels. For example, the influence of social networks in propagating ideas concerning vaccination has recently been shown [24], which can be considered as a potential issue for health authorities. Receiving information about the effectiveness of the vaccine through an informational meeting and from a nursing home physician has been shown to have a positive impact in different countries $[15,19,20]$. Nevertheless, despite a low IV coverage, NH workers felt they were sufficiently informed, $76.3 \%$ by the $\mathrm{NHs}$ and $67.5 \%$ by the media. Others means of communication have also proven their efficacy like personal reminders [25], newsletters [12], electronic mails, or dedicated websites [26]. However, being vaccinated was associated with having previously experienced a "severe" influenza episode in the past (PR 1.48, 95\% CI 1.01-2.17) which shows the differential impact between theoretical and practical knowledge of influenza infection consequences.

Recently, Corace et al. concluded that the Health Belief Model was a promising tool to measure the impact of behavioral changes on the increase of IV coverage among HCW [14]. Perceived benefits and barriers are modifying variables used in the Health Belief Model; however, other variables of this model were not taken into consideration in our study as we did not aim to investigate this concept more deeply. Thus, further studies need to be conducted to explore the outlooks regarding to perceived threats, selfefficacy, as well as cues to actions in order to increase IV uptake.

While being the first study in France to directly interview such a sample of $\mathrm{NH}$ workers regarding knowledge and opinions about IV, our study was subject to some limitations. NH participation rate was high (2 refusals out of $40 \mathrm{NHs}$ ), and $\mathrm{NH}$ workers refusal rate was limited to $1 \%$, but data collection was constrained by the fact that questionnaires had to be administered face-to-face during a single day. In addition, due to logistical issues, our study was performed in a single French department of Brittany (Ille-et-Vilaine). However, potential sociodemographic disparities within Brittany are unlikely to dramatically bias our results. Representativeness of Brittany with regards to France concerning $\mathrm{NH}$ workers vaccination is unknown, but to our knowledge, no known characteristics of the Region would impair our estimates at the national level. Although face-to-face interviews are an added value to our study, interviewers could have involuntarily influenced answers of $\mathrm{NH}$ workers, a bias minimized by interviewers' training. Finally, as the subject of this study may have been sensitive to some or all, approaching personal beliefs on vaccination might have made the personnel answer differently from their true opinions.
Despite these limitations, we show that access to vaccination is not likely to be a determinant of low IV coverage, since only $0.4 \%$ of the responders declared being vaccinated as time consuming and considering that $80 \%$ of the vaccinations occurred inside the facilities. In addition, although $17.1 \%$ of the respondents cited IV financial cost as a barrier, the vaccine is available for free (or reimbursed) for the recommended population. Hence, we may "only" face a vaccination "hesitancy" issue, a concern defined by WHO as a "delay in acceptance or refusal of vaccines despite the availability of vaccine services" [27, 28]. Addressing vaccine "hesitancy" is complex and requires targeting multiple potential determinants.

Since most of the personnel vaccination was performed inside NHs like most of the vaccine communication, improvements may have to be targeted at the work place. Indeed, better results are found with IV campaign using staff of mobile units [26], flexible day and time (OR 1.45 95\% CI 1.12-1.96) [12], and additional time slots during the day and night, $68.8 \%$ versus $41.4 \%$ [1].

The next step after influenza vaccine facilitation may be making it mandatory. Compulsory reassignment, wearing a mask or unpaid leave from work in case of refusal to get vaccinated are also different policies associated with a higher IV coverage $(p<0.002)$ [29]. In Norway, public opinion is in favor of freedom of choice (69\% among vaccinated, $92.4 \%$ among non-vaccinated) [30], so is the Dutch population $(77.6 \%$ and $96.5 \%$ respectively) [20]], but in the US, several hospitals have already made seasonal IV mandatory for HCWs with direct patient contact [15, 31]. Pre-post studies indicate that mandatory vaccination is successful in achieving near-universal vaccination rates of $95 \%$ to $98.5 \%$ [32], an idea defended by public health specialists for ethical and financial benefits reasons [33-35]. Since NHs have a moral responsibility to protect their residents, $\mathrm{NH}$ workers mandatory IV may have to be considered in the future if IV coverage remains low due to inefficiency of voluntary incitation measures.

\section{Conclusions}

Our study showed that NH workers IV maybe largely insufficient in western France and possibly throughout the country. High variations in IV coverage among $\mathrm{NHs}$ shows the key role of $\mathrm{NH}$ management and the working environment. Vaccine "hesitancy" may also be the main reason explaining this public health issue. Specific communication tools focusing on false beliefs should be developed and adapted to the various professional population, as well as the new modes of communication (social media). Failing to do so may pave the way to more debatable strategies such as compulsory IV. 


\section{Additional files}

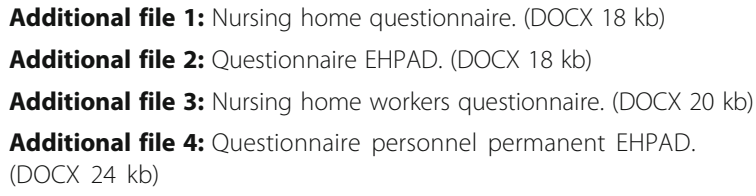

\section{Abbreviations}

ANSP: Santé Publique France; ARS: Agence Régionale de Santé; CDC: Center for Disease Control and Prevention; CESPA: Centre d'épidémiologie et de santé publique des armées; CI: Confidence interval; EHESP: French School of Public Health; HCW: Healthcare workers; IDEA: International field epidemiology training course; IV: Influenza vaccination; NHs: Nursing homes; OR: Odds ratio; PR: Prevalence ratio; WHO: World Health Organization

\section{Acknowledgements}

The authors would like to thank the directors of the NHs who authorized the survey and all their staff who took time to answer questionnaires. We warmly thank the participants to the 2016 applied epidemiology IDEA training for their involvement in all aspects of the study, and their teachers, particularly Delphine Antoine, Lisa King of Santé Publique France (ANSP). The authors also thank Dominique Le Goff and Pierre Guillaumot from Agence Régionale de Santé Bretagne (ARS) for fruitful discussions, Yann Le Strat from Santé Publique France for statistical support, and Narimane Nekkab from French School of Public Health (EHESP) for technical support. Finally, EHESP, ARS, ANSP, and the Centre d'épidémiologie et de santé publique des armées (CESPA) have to be acknowledged for their logistical support.

\section{Funding}

This study is based upon work supported by the French School of Public Health (EHESP) as well as Santé Publique France (ANSP).

\section{Availability of data and materials}

Not applicable.

\section{Authors' contributions}

All authors made a substantial contribution to the conception or design of the survey described in the article. $C E, A F, A V, N B, S E, B M$ and $P C$ contributed to the analysis and interpretation of data; CE and AF drafted the initial manuscript; RD, HT, YG and PC designed and coordinated the study. All authors read and approved the final manuscript.

\section{Ethics approval and consent to participate}

All participants have given their oral consent to participate to the study which had first been approved by the director of each participating nursing home. We consulted the legal and ethic department of Santé Publique France (the French National Agency for Public Health), who stated that the study falls under the definition of "non interventional" because it was "based exclusively on administering a questionnaire without any change in person care or in monitoring procedure". Hence, they state that this kind of "observational" study did not require the approval of an ethic committee (CPP).

\section{Consent for publication}

Not applicable.

\section{Competing interests}

$P C$ reports receipt of research funding from an influenza vaccine producer (Sanofi Pasteur) for studies on influenza vaccine effectiveness. CE, AF, AV, NB, $\mathrm{SE}, H T, Y G, R D$, and $B M$ declare that they have no competing interests.

\section{Publisher's Note}

Springer Nature remains neutral with regard to jurisdictional claims in published maps and institutional affiliations.

\section{Author details}

${ }^{1}$ Ecole des Hautes Etudes en Santé Publique, Université Sorbonne Paris Cité Rennes, France. ${ }^{2}$ Ecole Pasteur-CNAM de Santé Publique, Paris, France.
${ }^{3}$ Epiter, F-94415 Saint-Maurice, France. ${ }^{4}$ Santé publique France, Cellule d'intervention en région Bretagne, F-94415 Saint-Maurice, France. ${ }^{5}$ UMR "Emergence des Pathologies Virales", Aix-Marseille University - IRD 190 Inserm 1207 - EHESP, Marseille, France. 'EA 7449 Reperes, EHESP - Université de Rennes 1, Rennes, France.

Received: 9 August 2016 Accepted: 29 June 2017

Published online: 07 July 2017

\section{References}

1. Centers for Disease Control and Prevention (CDC). Influenza vaccination coverage among health-care personnel — United States, 2010-11 influenza season. MMWR Morb Mortal Wkly Rep. 2011;60(32):1073-7.

2. Vaccines against influenza WHO position paper - November 2012. Relevé Épidémiologique Hebd Sect Hygiène Secrétariat Société Nations Wkly Epidemiol Rec Health Sect Secr Leag Nations. 2012;87(47):461-76.

3. Hak E, Wei F, Nordin J, Mullooly J, Poblete S, Nichol KL. Development and validation of a clinical prediction rule for hospitalization due to pneumonia or influenza or death during influenza epidemics among communitydwelling elderly persons. J Infect Dis. 2004;189(3):450-8.

4. Jefferson T, Rivetti D, Rivetti A, Rudin M, Di Pietrantonj C, Demicheli V. Efficacy and effectiveness of influenza vaccines in elderly people: a systematic review. Lancet Lond Engl. 2005;366(9492):1165-74.

5. Hayward AC, Harling R, Wetten S, Johnson AM, Munro S, Smedley J, et al. Effectiveness of an influenza vaccine programme for care home staff to prevent death, morbidity, and health service use among residents: cluster randomised controlled trial. BMJ. 2006;333(7581):1241.

6. van den Dool C, Bonten MJM, Hak E, Heijne JCM, Wallinga J. The effects of influenza vaccination of health care workers in nursing homes: insights from a mathematical model. PLoS Med. 2008;5(10):e200.

7. Mitchell R, Huynh V, Pak J, Thompson S, Noseworthy AL. Influenza outbreak in an Ontario long-term care home-January 2005. Can Commun Dis Rep Relevé Mal Transm Au Can. 2006;32(21):257-62.

8. Bush KA, McAnulty J, McPhie K, Reynolds R, Boomer M, Clarkson LM, et al. Antiviral prophylaxis in the management of an influenza outbreak in an aged care facility. Commun Dis Intell Q Rep. 2004;28(3):396-400.

9. Wilde JA, McMillan JA, Serwint J, Butta J, O'Riordan MA, Steinhoff MC Effectiveness of influenza vaccine in health care professionals: a randomized trial. JAMA. 1999;281(10):908-13.

10. National Vaccine Advisory Committee. Strategies to achieve the healthy people 2020 annual influenza vaccine coverage goal for health-care personnel: recommendations from the national vaccine advisory committee. Public Health Rep Wash DC 1974. 2013;128(1):7-25.

11. Loi n² 2004-806 du 9 août 2004 relative à la politique de santé publique Article ANNEXE.

12. Pina P, Moreau AL, Duran A, Sadeg O, Mandelbaum B, Teixeira A. Acceptance of influenza vaccination by caregivers in a geriatric and longterm care institution. Médecine Mal Infect. 2008:38(11):595-600.

13. LaVela SL, Etingen B, Miskevics S. Attitudes toward influenza vaccination improvement strategies in veterans affairs health care workers providing care for patients with spinal cord injuries and disorders: acceptability of a declination form program. Vaccine. 2015;33(36):4602-9.

14. Corace K, Prematunge C, McCarthy A, Nair RC, Roth V, Hayes T, et al. Predicting influenza vaccination uptake among health care workers: what are the key motivators? Am J Infect Control. 2013;41(8):679-84.

15. Daugherty JD, Blake SC, Grosholz JM, Omer SB, Polivka-West L, Howard DH. Influenza vaccination rates and beliefs about vaccination among nursing home employees. Am J Infect Control. 2015;43(2):100-6.

16. Mehta M, Pastor CA, Shah B. Achieving optimal influenza vaccination rates: a survey-based study of healthcare workers in an urban hospital. J Hosp Infect. 2008;70(1):76-9.

17. Vaux S, Noël D, Fonteneau L, Guthmann J-P, Lévy-Bruhl D. Influenza vaccination coverage of healthcare workers and residents and their determinants in nursing homes for elderly people in France: a crosssectional survey. BMC Public Health. 2010;10:159.

18. Guthmann J-P, Fonteneau L, Ciotti C, Bouvet E, Pellissier G, Lévy-Bruhl D, et al. Vaccination coverage of health care personnel working in health care facilities in France: results of a national survey, 2009. Vaccine. 2012;30(31):4648-54.

19. Vaux S, Van Cauteren D, Guthmann J-P, Le Strat $Y$, Vaillant $V$, de Valk H, et al. Influenza vaccination coverage against seasonal and pandemic influenza 
and their determinants in France: a cross-sectional survey. BMC Public Health. 2011;11:30.

20. Looijmans-van den Akker I, van Delden JJM, Verheij TJM, van Essen GA, van der Sande MA, Hulscher ME, et al. Which determinants should be targeted to increase influenza vaccination uptake among health care workers in nursing homes? Vaccine. 2009;27(34):4724-30.

21. Takayanagi IJ, Cardoso MRA, Costa SF, Araya MES, Machado CM. Attitudes of health care workers to influenza vaccination: why are they not vaccinated? Am J Infect Control. 2007;35(1):56-61.

22. Guthmann J-P, Fonteneau L, Bonmarin I, Lévy-Bruhl D. Influenza vaccination coverage one year after the a(H1N1) influenza pandemic, France, 20102011. Vaccine. 2012;30(6):995-7.

23. Bone A, Guthmann J-P, Nicolau J, Lévy-Bruhl D. Population and risk group uptake of H1N1 influenza vaccine in mainland France 2009-2010: results of a national vaccination campaign. Vaccine. 2010;28(51):8157-61.

24. Salathé $M$, Khandelwal $S$. Assessing vaccination sentiments with online social media: implications for infectious disease dynamics and control. PLoS Comput Biol. 2011;7(10):e1002199.

25. Lee SJ, Harrison R, Rosenberg J, McLendon P, Boston E, Lindley MC. Influenza vaccination among health care personnel in California: 2010-2011 influenza season. Am J Infect Control. 2013;41(8):e65-71.

26. Llupià A, García-Basteiro AL, Olivé V, Costas L, Ríos J, Quesada S, et al. New interventions to increase influenza vaccination rates in health care workers. Am J Infect Control. 2010;38(6):476-81.

27. WHO. Report of the Sage Working Group on Vaccine Hesitancy. 2014.

28. ECDC. European Centre for Disease Prevention and Control. Vaccine hesitancy among healthcare workers and their patients in Europe - A qualitative study. 2015

29. Nowalk MP, Lin CJ, Raymund M, Bialor J, Zimmerman RK. Impact of hospital policies on health care workers' influenza vaccination rates. Am J Infect Control. 2013:41(8):697-701.

30. Bentele H, Bergsaker MR, Hauge SH, Bjørnholt JV. Vaccination coverage for seasonal influenza among residents and health care workers in Norwegian nursing homes during the 2012/13 season, a cross-sectional study. BMC Public Health. 2014;14:434.

31. Stewart AM, Cox MA. State law and influenza vaccination of health care personnel. Vaccine. 2013:31(5):827-32

32. Septimus EJ, Perlin JB, Cormier SB, Moody JA, Hickok JD. A multifaceted mandatory patient safety program and seasonal influenza vaccination of health care workers in community hospitals. JAMA. 2011;305(10):999-1000.

33. Poland GA. Mandating influenza vaccination for health care workers: putting patients and professional ethics over personal preference. Vaccine. 2010; 28(36):5757-9.

34. Ottenberg AL, Wu JT, Poland GA, Jacobson RM, Koenig BA, Tilburt JC. Vaccinating health care workers against influenza: the ethical and legal rationale for a mandate. Am J Public Health. 2011;101(2):212-6.

35. van Delden JJM, Ashcroft R, Dawson A, Marckmann G, Upshur R, Verweij MF. The ethics of mandatory vaccination against influenza for health care workers. Vaccine. 2008;26(44):5562-6.

\section{Submit your next manuscript to BioMed Central and we will help you at every step:}

- We accept pre-submission inquiries

- Our selector tool helps you to find the most relevant journal

- We provide round the clock customer support

- Convenient online submission

- Thorough peer review

- Inclusion in PubMed and all major indexing services

- Maximum visibility for your research

Submit your manuscript at www.biomedcentral.com/submit
Biomed Central 